\title{
O SIMBÓLICO EM EDITH STEIN: UMA APROXIMAÇÃO COM A GEOGRAFICIDADE
}

\author{
The Symbolic in Edith Stein: an Approximation to Geographicity
}

El Simbólico en Edith Stein: una Aproximación con la Geograficidad

ViRginia LiMA PaLHARES

\begin{abstract}
Resumo: O pensamento antropológico de Edith Stein está ancorado na fenomenologia de Husserl. Ele está voltado basicamente para conhecer e explicar a pessoa humana em profundidade. A filósofa aborda os conceitos de comunidade e empatia para compreender o ser pessoa. Em sua fase religiosa, Stein se inspira em Teresa D’Ávila e São João Batista da Cruz para clarificar a experiência mística e seus símbolos. Pretende-se, neste texto, compreender como Edith Stein explora o simbólico e o mítico em seus escritos espirituais. Serão investigados, ainda, os símbolos apresentados por Edith Stein que podem se relacionar com a geograficidade, termo criado por Eric Dardel, para explicar a profunda relação existente entre o homem e a Terra. Torna-se um desafio aproximar as ideias de Edith Stein durante sua fase religiosa ao pensamento de Eric Dardel sobre a própria possibilidade de ser no mundo através das profundas vinculações existenciais entre o homem e a Terra.
\end{abstract}

Palavras-chave: Geograficidade; Simbólico; Experiência; Místico.

Resumen: El pensamiento antropológico de Edith Stein tiene base en la fenomenología de Husserl. Él se dedica básicamente a conocer en profundidad e explicar la persona humana. Según la filósofa, la persona humana se explica por su interioridad y su espiritualidad. Los conceptos de comunidad e empatía serán abordados para comprender el ser persona. En su período religioso, Stein se inspira en Teresa de Ávila y San Juan Bautista de la Cruz para tornar clara su experiencia mística y sus símbolos. En este texto se pretende comprender como Edith Stein ve la persona humana y como discute los símbolos en sus escritos espirituales. Así pues, se pretende mostrar aspectos simbólicos discutidos por Edith Stein que pueden relacionarse con la geograficidad, término creado por Eric Dardel para explicar la profunda relación existente entre el hombre y la Tierra.

Palabras-clave: Geograficidad; Simbólico; Experiencia; Místico.

Abstract: Edit Stein's anthropologic thinking is based on Husserl's phenomenology. Its purpose is basically to know in depth and explain the human individual. According to philosophy, interiority and spirituality explain the human individual. She will approach the concepts of community and empathy to understand the individual. On its religious phase, Stein gets inspiration from Teresa D’Ávila and São João Batista da Cruz to clarify the mystic experience and its symbols. The objective of this text is to understand how Edith Stein sees the human individual and how she discusses the symbolic in its spiritual writing. Finally, this text seeks to how the symbolic aspects shown discussed by Edith Stein that can be related to geographicity, word created by Eric Dardel to explain the profound existing relation between man and the Earth.

Keywords: Geographicity; Symbolic; Experience; Mystic.

\section{Introdução}

O momento em que vivemos é marcado pelo individualismo. Os relacionamentos são tecidos com fios frágeis. Interesses pessoais sobrepõem a interesses coletivos. Não se pensa em construir uma relação sensível de amor à Terra. Não se cogita conhecer a Terra em sua essência. Percebe-se, no pensamento de Edith Stein, a possibilidade de se realizar uma aproximação com a geograficidade. É conhecendo a estrutura da pessoa humana e os aspectos simbólicos e místicos próprios da espiritualidade descritos por Stein que será possível compreender a relação íntima com a Terra tão bem delineada pelo geógrafo Eric Dardel. Neste texto, o propósito é compreender como Edith Stein, inspirada nos princípios husserlianos, compreende a pessoa humana e de que modo ela influencia nas relações interpessoais do cotidiano em comunidade e como ela discute o simbólico em seus escritos espirituais. A filósofa dialoga com a fenomenologia de Husserl e o pensamento de Tomás de Aquino. Esta iniciativa causa surpresa no círculo de filósofos da época pois não se cogitava aplicar a fenomenologia a temas que não estariam diretamente relacionados com a epistemologia científica tais como a pedagogia e a vida mística. Stein nos revela o pensador Tomás de Aquino, pluralista, capaz de dialogar com a filosofia independente de sua crença. É bom lembrar que a filósofa percorreu um longo caminho fenomenológico antes de se debruçar nos caminhos à procura da verdade.

Ademais, a experiência sempre foi um recurso utilizado para exprimir aquilo que se manifesta e conseguir estabelecer as relações entre o vivido e o encontro com o outro, mostrando as suas particularidades, as suas 
diferenças. Até mesmo durante a experiência mística, a presença de Deus é vista como vivência e não como uma abstração. Em sua fase religiosa, Stein se inspirou em Teresa D’Ávila e São João Batista da Cruz para clarificar a experiência mística e seus símbolos.

Ao fim, pretende-se mostrar aspectos simbólicos discutidos por Edith Stein que podem se relacionar com a geograficidade para explicar a profunda relação existente entre o homem e a Terra. O trabalho se inicia mencionando o método fenomenológico presente, especialmente, durante a etapa fenomenológica de Stein para, em seguida, comentar sobre a realidade relacional sempre presente em seu pensamento e, por fim, buscar a relação entre geograficidade e o simbólico em sua fase espiritual. A investigação concentrou-se nas "Obras Completas (Tomo V - Escritos espirituales: en el Carmelo teresiano 1933-1942) de Edith Stein, mais precisamente sobre o "Castelo Interior", nos Caminhos do Conhecimento de Deus e na Ciência da Cruz. Em "O Castelo Interior” Stein traz à cena a essência do ser humano em sua interioridade através das experiências místicas vividas por Teresa D’Ávila. Ela se apropria de símbolos e de uma linguagem poética para revelar sua aproximação com a verdade. Nos Caminhos do Conhecimento de Deus prevalece a busca do sentido do ser em sua profundidade para se alcançar um ser absoluto, eterno. Ali, Edith comenta sobre a formação do pensamento de Tomás de Aquino e mostra a relevância da vida mística e da contemplação a Deus. A fé, neste sentido, é indispensável para nos conduzir a estes caminhos misteriosos da presença de Deus em nós. Por fim, na Ciência da Cruz, a simbologia poética de São João da Cruz se revela pelo sentido da cruz e da noite escura. O símbolo apresenta algo sagrado, aquilo que se manifesta; ao se interiorizar, se transforma em estímulo para mudar a própria alma. O que ocorre é que São João da Cruz utiliza da simbologia da noite cósmica para explicar a noite mística, originada no íntimo da alma.

\section{Primeiras aproximações: a experiência}

As contribuições de Edith Stein são tantas e tão densas que as descobertas são constantes. A cada página virada de sua obra há uma abertura para se conhecer melhor a pessoa humana e para se viver a experiência geográfica. Estou me preparando para o outro na medida em que me abro para mim. Penso que a empatia pode se relacionar à realidade geográfica de Dardel (2011). A empatia é, pois, acompanhando o pensamento steiniano (2004), uma oportunidade de vivência comum ao eu e ao outro; é uma realidade. A vivência empática possibilita ao eu perceber imediatamente a presença do outro, reconhecendo-o por meio da intuição. A vivência ocorre no corpo e quanto maior a sua intensidade, mais viva se torna a consciência que se tem dela. A empatia é, nesse sentido, uma vivência que nos une ao outro.
A realidade geográfica requer um envolvimento da pessoa com suas emoções, seu corpo, seus hábitos, seu chão. Onde está a cotidianidade, o homem sente cheiros e cores deste chão carregado de significados e valores imprimidos por nossa íntima relação com ele. Vejo a Terra de Dardel muito além do solo que nos sustenta. Vejo a Terra com o sentido de chão sobre o qual são criadas raízes ao longo do tempo, testemunhos de nossa história; ali estão nossas origens, nossa história. Vejo a Terra como mater, o despertar para a vida, que protege, abriga, afaga, resgata a nossa essência, a nossa origem. É, assim, “...aquilo sobre o que e em que o homem funda seu morar" (Heidegger, 2010, p. 105), onde a Terra conserva o mundo em si mesma (Heidegger, 2010). Habitamos a Terra. Mundo e Terra são distintos, embora estejam entrelaçados. O mundo busca se apoiar na Terra e esta, por sua vez, brota enquanto mundo. Heidegger (2010) acrescenta que "o mundo aspira, no seu repousar sobre a Terra, a fazê-la sobressair. Ele não tolera, como o que se abre. Porém, a Terra tende, como a que abriga, cada vez a abranger e a conservar em si o mundo" (Heidegger, 2010, p. 121).

Mas ainda não sei o que me aguarda. Sei apenas que tenho o compromisso, como todos aqueles que se dedicam à obra de Stein, de difundir o seu pensamento, dar voz às suas angústias e clarificações e despertar, naqueles que compartilham o humanismo, as possibilidades de trabalho em comum união com suas ideias.

A busca de Edith Stein pela formação do ser humano se dá por meio da fenomenologia husserliana. Segundo o método, o conhecimento das coisas tem início com a experiência que se tem delas. O projeto de Husserl se concentra na essência da resposta à pergunta: $\mathrm{O}$ que é? para alcançar a verdade. A pergunta originária "Que é o homem?", e a sua procura pela verdade perpassou toda a existência de Stein. A resposta a este questionamento deverá apresentar o homem em sua essência que, segundo a filósofa é composta por forma e matéria. É aquilo que se encontra no ser, próprio da pessoa; é a sua verdade e basta-se no que se é.

Tomar consciência de si e viver de modo empático leva a uma transformação do ser humano. No pensamento steiniano é preciso haver uma relação para ser pessoa diferente dos outros seres da natureza, porque ela é tecida por três fios: corpo, alma ou psique e espírito, dimensões conformadoras de um todo. O primeiro fio abrange um corpo vivente porque tem matéria, psique e consciência. Neste corpo há um eu com sensações; um eu que sente e possui liberdade para agir. A alma é ser vivente, formado e transformado a partir de seu interior. O segundo fio é mediador do corpo e do espírito. A alma se torna, então, o principal fio a ser entrelaçado para dar unidade à pessoa. A alma faz parte da interioridade onde o eu tem consciência e liberdade para decidir seus atos. Ao mesmo tempo, difunde atos espirituais que lhe permite captar as coisas do mundo e aquilo que transcende. A alma nos faz voltar para nós mesmos, pois "é o centro da pessoa, o 
'lugar' onde ela está em si mesma” (Stein, 2004, p. 811). Por último, o terceiro fio - o espírito - compõe a tessitura da pessoa humana. O espírito se abre para algo, toma consciência, se utiliza do corpo para a realização da vivência empática. É nele que se encontra o núcleo da alma.

A tessitura dos fios forma, então, o tecido vivo, o ser pessoa, consciente de si, de sua vida. É pensar o homem em sua individualidade para depois pensar sua relação com o outro, traduzindo em uma comum unidade. De fato, a comunidade se constrói de indivíduos. Nas palavras de Stein (2004), "quando um sujeito aceita o outro como sujeito e não só está diante dele, mas vive com ele é determinado por seus movimentos vitais, neste caso os dois sujeitos constituem entre si uma comunidade" (Stein, 2004, p. 344). Viver em comunidade é ver as pessoas atuarem, mas também estar com elas em sua cotidianidade. É ser potencialmente solidário. Isto significa que uma comunidade não é apenas formada por um grupo de pessoas, mas é uma comum união de pessoas que vivem, sentem e atuam como parte integrante de seu espaço de vida. Stein comentou, em vários momentos de sua obra, que indivíduo e comunidade estão sempre em processo, sempre em movimento, sempre se fazendo.

O método fenomenológico esteve presente em todas as fases de sua vida, até mesmo quando a filósofa já se encontrava na fase religiosa e mística. Sempre demonstrou a essência de seu pensamento fundamentada em Husserl, ainda que de forma velada. Stein nunca deixou a chama da fenomenóloga se apagar dentro de si; ao contrário, ela se manteve viva através da experiência e da busca pelo sentido originário das palavras até penetrar nas coisas mesmas. Isto pode ser verificado até em sua última reflexão - Ciência da Cruz -, quando se refere à experiência da paixão de Cristo como uma aproximação a Deus. E a experiência de Edith se revelou em Auschwitz, local de vivência do sofrimento, mas também de libertação e aproximação com Deus.

A religiosidade de Stein é uma realidade relacional e, portanto, experiencial. Não há vivência autêntica sem um encontro, sem uma experiência, sem um mergulho no mistério. Deus e, também, o ser humano, são mistério. O encontro empático com Deus, através de seus sentimentos, vai marcar sua vida cristã. Edith passa a conhecer-se e a Deus, por sua vez. Ela resgata o conceito de empatia discutido em "Sobre o problema da Empatia" (El Problema de La Empatía, 2004), no início de sua carreira profissional, ao acolher a experiência do outro, vivida em uma dimensão de fé experiencial; se converte para viver o amor ao próximo. Um exemplo do pensamento fenomenológico e antropológico em Stein diz respeito às suas reflexões espirituais. Na sua busca pela compreensão da verdade, ela sempre parte do homem, do que está próximo de nossa experiência imediata, para o alto, para Deus, para seu mistério. Dessa perspectiva, o conhecimento do homem se abre em direção ao mistério. O homem olha para o alto como o único que pode dar resposta à verdade de seu ser, de sua existência. Em Stein tudo vai ao encontro da unidade e tudo parte desta unidade. Deus é reconhecido naquilo que se revela e os espíritos, aos que se revela, transmitem esta revelação. A ascensão a Deus se faz pela obscuridade e pelo silêncio. E ela se faz pela vivência mística, compreendida por Stein como a conversa interior com Deus que assegura a sua presença; "é o núcleo de toda vivência mística: o encontro com Deus de pessoa a pessoa" (Stein, 2004, p. 149), com diferentes intensidades. O sentimento da presença de Deus vem a ser o núcleo de toda experiência mística; é ser tocado, sem ver, sem ouvir, sem falar, sem imagens. É sentir. Esse encontro íntimo da pessoa com Deus se faz revelar por uma imagem e palavras que podem se revelar e mostrar um Deus tal qual lhe foi conhecido.

\section{Aproximações: a simbologia}

Ao longo de sua vida Edith Stein teve sua base filosófico-religiosa fundamentada em Agostinho, Tomás de Aquino, Ignácio de Loyola, Teresa D’Ávila e São João da Cruz. Mas foi com estes dois últimos que Stein conheceu a verdade. Ambos eram espanhóis, contemplativos, carmelitas descalços. Edith vê a mística como uma experiência da pessoa relatada como um testemunho dessa experiência. E é aqui que me apoiarei para tecer a fenomenologia geográfica em Stein.

Castelo Interior, mariposa, água, cruz e noite escura: identifiquei em Edith Stein estes símbolos místicos com mais frequência quando ela relata a experiência pessoal de Teresa D’Ávila e São João da Cruz. Cada um destes símbolos revela o sagrado por meio da utilização de uma linguagem poética. Ela procura significar, ou melhor, (re) significar os termos por ela utilizados. E para deslindar a linguagem simbólica, reconhece a imagem não apenas como aquilo que é próprio do artista, que interiormente lhe provoca emoções, mas também, qualquer criação artística. Ainda no rastro de suas palavras, a arte autêntica simboliza a intenção do artista e aqui, “o ‘símbolo’ é mais que isto, pois representa a plenitude infinita do sentido que avança todo conhecimento humano" (Stein, 2004, p. 208), capta algo, o manifesta e o expressa; e faz ecoar misteriosamente a plenitude de sentido. Assim, "toda arte autêntica é 'revelação' e toda criação artística, um serviço santo" (Stein, 2004, p. 208). O que se pretende dizer é que, por exemplo, não há apenas um artista que não tenha se sentido impulsionado a representar um Cristo na cruz ou o Cristo com a cruz nas costas embora o crucificado espere do artista algo mais que uma imagem.

Teresa D’Ávila utiliza uma linguagem metafórica para descrever o "Castelo Interior" em 1577, sua principal obra mística, na tentativa de torná-la mais compreensível. A construção desta imagem surge, nesse momento, como uma maneira encontrada para explicar sua interioridade a partir da experiência. O discurso simbólico é, aqui, 
expressão do conhecimento simbólico. "Precisamente me parece que isto que hoje se entende pelo termo 'símbolo', se realiza plenamente quando uma figura expressiva é captada como 'imagem sensível', abrindo-nos a imagem a um sentido até agora desconhecido” (Stein, 2004, p. 144), o próprio mistério.

Pretendo aqui apenas resgatar a imagem do "Castelo Interior” e conecta-la à pessoa humana uma vez que a compreensão de alma é fundamental na construção físico-psico-espiritual que Edith chama de homem. Além disso, é interessante observar o sentido de amplidão que Santa Teresa dá à alma, "tão ampla quanto o mundo" (Stein, 2014, p. 247), este mundo que o ser é. A alma possui um ser, uma natureza espiritual; une o espírito ao corpo. Temos que tomar como base as experiências e testemunhos místicos para entendermos a interioridade humana. O “Castelo Interior” é uma demonstração disso. Santa Teresa, pela sua própria experiência, alcançou o mais alto grau de vida mística após uma ação de disciplina espiritual, pela sua capacidade de expressar suas vivências interiores e o indescritível através dos símbolos. Estes são considerados símbolos místicos ou espécies de moradas nas quais deveríamos viver.

Santa Teresa descreve a sua vivência mística se utilizando de uma linguagem metafórica. Ela explica a existência de um castelo cercado por uma muralha. “(...) A própria alma é o castelo” (Teresa de Ávila, 2015, p. 20). Como entrar neste castelo sendo ambos uma unidade, uma mesma coisa? É o mesmo que dizer a uma pessoa para entrar na sala embora ela já se encontre nela. A muralha é o corpo e, nele, há sete aposentos ou moradas construídos em andares que, se adentrados, se alcança a alma, ao núcleo mais íntimo do homem, a alma da alma, como Stein (2004) se referia. Fora da muralha há o mundo externo: quem o habita desconhece a vida que se desenvolve no interior do castelo e "é mesmo estranho que uma pessoa não conheça a própria casa” (STEIN, 2004, p. 105).

O castelo se encontra no topo de um morro, isolado, livre de inundações e invasões e está entre o céu e a terra. É a ligação entre o homem e Deus. Teresa parte do princípio que a felicidade denominada por ela de Deus, está em cada um de nós e é, portanto, um estado de consciência cujo desabrochar requer se conhecer. Para penetrar nesta consciência é preciso haver uma experiência que caracteriza o saber místico, uma introspecção, um retorno ao eu. Primeiro é preciso entrar no castelo, voltar-se para si, conhecer-se; afinal, "não se pode levantar os olhos a Deus sem ser conscientes da própria baixeza. Mediante o próprio conhecimento nos aproximamos de Deus" (Stein, 2004, p. 82). Nem sempre as pessoas conseguem perceber e até mesmo entrar no castelo devido ao fascínio exercido pelo mundo exterior. A chave para abrir a porta e entrar no castelo é a oração e a reflexão para saber olhar para si, para se conhecer; para entrar nos aposentos é preciso possuir a virtude da humildade e a devoção. Assim, a primeira morada ou aposento retrata ainda uma forte relação do ser humano com o exterior e se torna desafiadora pela escolha de um caminho espiritual.

Quando atinge a segunda morada, a alma já percebe certos chamados de Deus através do mundo exterior e a faz refletir e entrar mais em si mesma. Está determinada a percorrer o caminho até Deus. Muitas almas circundam o castelo, mas não conseguem entrar porque não possuem a consciência de se conhecer.

A terceira morada fundamenta-se na aceitação dos apelos da segunda morada. Teresa reforça a importância da humildade para continuar a longa caminhada até Deus - Sua Majestade - que se encontra na sétima morada ou aposento. Acrescente-se que a meditação se torna uma prática cotidiana embora ocorra ainda muitos apelos externos ao castelo. Nesta morada,

Não se trata de vozes interiores, mas de reclamações que vêm de fora e que ela percebe como uma mensagem de Deus como palavras de um sermão, ou paisagens de um livro que pareciam ditos ou escritos precisamente para ela, enfermidades e outros casos providenciais. A alma vive, todavia, em e com o mundo, mas estas chamadas penetram em seu interior e a convidam a entrar em si. (Stein, 2004, p. 83)

Nas três primeiras moradas há impurezas infiltradas pelos órgãos dos sentidos, como o orgulho, a avidez, a vaidade, em razão da proximidade da entrada do castelo. Quem entra nessas moradas deve fazer uma limpeza, se purificar, penitenciando-se de suas falhas.

A quarta morada (oração) é iluminada. A alma deixa de pensar e passa a amar; "a oração de quietude brota sem nenhum esforço próprio” (Stein, 2004, p. 84); é espontânea. A oração cria a relação empática entre Deus e a consciência e Ele se faz presente pela revelação. Ela traz contentamentos resultantes dos momentos de meditação. Os contentamentos mostram quando a alma faz alguma coisa por Deus. O mais importante "para tudo, é o ter ciência e letras” (Teresa de Ávila, 2015, p. 72). O desejo de contentar a Deus leva ao exercício do amor e não propriamente o pensar.

Na quinta morada (experiência mística), a alma recebe a marca do amor incondicional. É o sair de si. "A santa descobre, pela experiência interior, uma verdade de fé que ignorava até o momento. Deus está em todas as coisas por presença e por potencia e essência” (Stein, 2004, p. 87). Foi nesse estágio que Santa Teresa teve revelações e esteve em êxtase, chamado por ela de voos do espírito, saídas de si. Teresa D’Ávila explica que estas saídas de si, correspondem ao desprendimento da alma do corpo, ainda que a pessoa não tenha morrido. As revelações são visões, intuições da presença divina, e não propriamente visões materializadas no sentido físico. Nossa consciência capta a presença divina sem haver mediação dos sentidos.

Nesta morada, Teresa cria uma linguagem metafórica para estabelecer uma relação simbólica com a mariposa 
e a crença no Divino. Como não crer no Divino? Como não crer na vida, na sua existência, quando se vê o modo de criar a seda? Quando uma semente brota nas folhas das amoreiras cobrando vida e, até então, estava morta. "Nas folhas, se cria o verme; e vai fiando a seda que tira de si mesmo e tece um pequeno casulo. Do verme nasce uma borboletinha branca.” (Teresa de Ávila, 2014, p. 81). Aqui, Teresa evidencia as transformações da alma decorrentes de um profundo processo de conhecimento interior. A alma, neste aspecto, fica propensa a atingir moradas mais elevadas.

Ela se pergunta: quais razões haveria para imaginar que um verme seja tão empenhado para trabalhar em nosso proveito e, ao final, o bichinho perca a sua vida? Uma alma que morre em seus descuidos e pecados precisa de remédios se quiser reviver; deve se sustentar com meditações e boas leituras. Crescendo, este verme começa a lavrar a seda e construir a casa onde há de morrer e, para nós, esta casa é Cristo. Do verme sai uma mariposinha branca. Fato semelhante ocorre à alma que, nesta oração, bem morta está ao mundo. A mariposinha não sabe onde pousar e fazer assento.

Foi tanto o que desfrutou que tudo quanto vê na terra a deixa insatisfeita. Já tem em nada as obras que fazia em outros tempos, sendo verme, que era ir pouco a pouco fiando seu casulo. Nasceram-lhe asas; como se contentará de ir passo a passo, se pode voar? (Teresa de Ávila 2015, p. 109)

Na sexta morada a alma esquece de si; a contemplação faz parte da habitualidade e a alma roga pelo sofrimento, pela conversão dos pecadores. Esta morada consiste no matrimonio com a divindade uma vez que os sentidos corporais externos são suspensos, mas as tribulações terrenas a tornam uma noite escura.

A sétima morada (união mística) expressa o desejo de fazer a vontade de Deus e trabalhar pele salvação das almas, inclusive pela própria; é o melhor fruto da união com a divindade. Em outras palavras, ocorre a divinização da alma, purificada, fortalecida, iluminada, que passa a desfrutar da paz. A alma se reconhece como instrumento para servir ao próximo.

Outro momento de relação íntima da Terra com a espiritualidade se expressa quando Teresa se refere à água como símbolo da purificação, como presença divina. Ela supõe duas situações: duas fontes de água que abastecem e enchem dois reservatórios. No primeiro, a água vem de longe através de canais feitos pelas mãos de homens. No outro, a água brota em borbulhas suaves, arredondadas, no próprio olho d'água e vai enchendo com muita mansidão. Quando este reservatório enche, transborda e, naturalmente, forma um grande córrego. A água está sempre despontando e não depende de canal para conduzi-la. Assim, no campo da espiritualidade, aqueles que precisam de reflexões e de meditações se comparam à água trazida por canais e fazem ruídos quando enchem a alma. Na outra fonte temos Deus, chamado por Teresa de Sua Majestade. Ele faz brotar paz e suavidade do mais íntimo da alma. "Não sei dizer para onde vai essa água, nem como brota; nem esse contentamento e deleite, ao menos no princípio, se sente no coração, como os da terra; só depois é que enche tudo" (Teresa de Ávila, 2014, p. 80). No Castelo Interior, a água purifica, flui para todos os aposentos e potências até chegar ao corpo, limpando-o, lavando-o, curando-o, sacralizando-o.

De fato, os símbolos e imagens, criados na realidade geográfica de Dardel (2011) se manifestam de muitas maneiras. Em uma delas, a superfície da água refletida na forma de qualquer corpo d'água emerge na contemplação do mundo por ela e se rende ao lirismo e à poética. O jogo de luzes e sombras criado pelos raios do sol desperta a imaginação para enxergar imagens telúricas. Quando Dardel (2011) comenta sobre o espaço aquático, ele apresenta um espaço discreto, reservado, tranquilo, cujas águas apenas murmuram ruídos que nos fazem abstrair a realidade geográfica. Assim, ela

(...) mistura as imagens que se levantam das profundezas e aquelas que se referem ao céu ou à costa. A intimidade da substância liquida suaviza o dourado frio do reflexo, e cria um mundo de formas moventes que parecem viver sob o olhar. (Dardel, 2011, p. 37)

Este mundo de formas moventes proporciona uma espécie de devaneio àquele que contempla a superfície cristalina do espelho d'água que serpenteia na paisagem verdejante. Na avaliação de Edith Stein (2004), Teresa de Ávila torna compreensível a sua experiência: a alma é atraída cada vez mais a si mesma até que finalmente Ele possa uni-la no interior dela mesma.

A geograficidade, entendida como a experiência do ser no mundo, como a sua relação no mundo, manifesta-se, a partir de agora, nos diálogos estabelecidos por Stein com Teresa e São João da Cruz. O sagrado, o simbólico, o místico, abraçam, envolvem toda a fase espiritual steiniana embora, nem sempre, de forma clara. João se dedica ao encontro com Cristo por meio da cruz e procura desvendar os mistérios da cruz, da morte, da ressureição.

Saindo do "Castelo Interior" em direção à noite escura e à cruz, investigadas por Edith Stein na Ciência da Cruz, vamos nos deparar com João, espanhol, místico e poeta. As vivências místicas de João da Cruz mostram um sentimento de amor e, ao mesmo tempo, de sofrimento, de dor pelo outro. "A contemplação do sofrimento da cruz" (Stein, 2014, p. 219) foi o meio encontrado para se alcançar a saída de si. Cristo se revela crucificado.

Cruz e noite indicam o caminho até a luz celestial. Estes símbolos consistem basicamente nos fundamentos místicos e simbólicos deixados por João. Cabe aqui reforçar o entendimento de símbolo explicado por Stein no sentido amplo como “(...) algo visível que estende seu 
significado a outra coisa invisível” (Stein, 2014, p. 234). Entretanto, este não é o sentido da noite; ela é algo natural, não é um objeto e a percebemos unida a nós. "Como a luz, penetra todas as coisas com suas propriedades visíveis” (Stein, 2014, p. 234).

Na descrição de Stein sobre a noite de João da cruz, verifica-se um esclarecimento sobre a noite cósmica e a noite simbólica do místico. Ainda que ambas possuam suas especificidades e até mesmo alguma proximidade, a noite cósmica detém a presença suave da lua. Essa, portanto, possui a presença iluminada da lua enquanto a noite escura traz tranquilidade e descanso. Noite mística e noite cósmica. No contexto de João da Cruz, ambas têm em comum a linguagem poética. A noite mística está na interioridade, está no eu e, nesse sentido, afeta a alma. Mesmo assim, os efeitos que ocorrem no interior podem ser comparados aos efeitos da noite cósmica, pois “(...) implica um desaparecimento do mundo exterior mesmo que o exterior se encontre na clara luz do dia” (Stein, 2014, p. 236). Estabelece um vazio na alma solitária que impede o desenvolvimento de suas potências e abre espaço para a angústia e o medo. Stein vê esse movimento como uma luz noturna que abre possibilidades para outra realidade no mais íntimo do ser, transbordando sua luz para o exterior. Stein esclarece, ainda, que a imagem é o aspecto determinante para explicar a relação existente entre noite cósmica e noite mística. A imagem da noite corresponde, a princípio, à noite cósmica e dela se transfere à mística, pois contribui para compreender algo desconhecido. Trata-se de um modo de apreender o espiritual através de algo sensível e conhecido como é a noite cósmica. Assim, para sintetizar, “(...) a noite é a necessária expressão cósmica da mística cosmovisão de São João da Cruz" (Stein, 2014, p. 237).

É da noite que nascem o lirismo, o simbolismo e o mais secreto de sua mística, que incorpora uma intuição do universo. A noite escura expressa um itinerário de amor cujas estrofes traduzem o movimento que vai unindo a amada e o Amado; a noite é a guia. João da Cruz refletiu sobre a experiência mística por meio de imagens do mundo sensível e conferiu a força da carne e o tempo às suas experiências espirituais. Na análise de Stein (2014), há uma luz que se abre no fundo da alma; um mundo novo, límpido, que reflete nas atitudes.

A noite do seu pensamento místico possui uma forte simbologia. Ela guarda uma relação com a experiência e vem acompanhada de sentimentos que lembram imagens sempre novas. Para João da Cruz, o símbolo da noite expressa uma profundidade imensa e um estado de ânimo muito particular que aponta as obscuras e misteriosas vias que conduzem a amada para a suave união divina. A noite torna-se, para o místico, um símbolo capaz de gerar novas situações e emoções que são captadas aos poucos: a princípio, apenas o ambiente em que a alma solitária começa sua caminhada; o guia entre o amante e o amado.
Dardel (2011), por sua vez, considera a noite a essência verdadeira da Terra a ser desvelada, tornando-a escura, sombria, misteriosa. É o fundo do escuro, a essência da Terra, o núcleo; esconde algo em cada um dos seres no momento em que eles se expõem à luz. Segundo ele, "é essa luta incessante entre a luz e a escuridão, entre o Homem e a Terra” (Dardel, 2011, p. 43), entre o sol e a lua, com características obscuras, das profundezas, com seus segredos, seus mistérios, que confere à estrutura humana o que ela tem de concreta e de real. "O homem procura a terra, ele a espera e a chama com todo o seu ser" (Dardel, 2011, p. 43) para estar no mundo.

A contemplação mística purificadora precisa da travessia da alma na noite escura para se sentir tocada por Deus. Ele comunica à alma seu amor, mas, ainda assim, permanece envolto no mistério; mistério este que transcende as alegorias da experiência para a alegoria do amor humano com o Divino.

A "Cruz e noite" há relação? Qual o sentido da cruz? Edith reconhece o símbolo como a "plenitude infinita do sentido sobre o qual avança todo conhecimento humano, capta algo e o faz manifesto e o expressa" (Stein, 2004, p. 237). A cruz, ao ser denominada de "imagem simbólica é símbolo no sentido amplo, algo visível que estende seu significado a outra coisa invisível” (Stein, 2004, p. 234). A cruz vai recebendo significados ao longo da história. Ela é um instrumento preparado e utilizado pelo homem com uma determinada finalidade. Através de sua figura visível, a cruz nos leva, então, à plenitude do significado que está unido a ela. É simbólica, se torna sagrada. "É, portanto, um signo, mas um cujo significado não lhe tenha sido aplicado artificialmente, mas que realmente provém do fundamento de sua eficácia e de sua história” (Stein, 2004, p. 234).

Diferente da cruz, a noite é algo natural: o contrário da luz, que nos envolve a todas as coisas. Edith explica que a noite "não é um ‘objeto' no sentido literal da palavra: não está diante de nós e nem sequer se sustenta por si mesmo. Não é tão pouco uma 'imagem”' (Stein, 2004, p. 234). Ainda assim, percebemo-la e está mais próxima a nós que todas as coisas e figuras. A noite é como a sombra, um fantasma: invisível e, por isso, ameaçadora, assustadora. Nosso ser não só está ameaçado exteriormente por perigos ocultos na noite, mas também interiormente, afetado pela noite mesma. Nosso ser sente suas forças reduzidas, é atirado à solidão e converte-se em sombras e fantasmas. É como antecipar a morte, vista na geografia mítica de Dardel (2011) apenas como um modo de existência ou no máximo uma mudança de forma ou de residência. Lá, "os defuntos, os ancestrais e os deuses vivem ao lado dos seres humanos” (Dardel, 2011, p. 53). Seres angelicais ou demoníacos, duendes, fadas, vampiros, magos; todos eles habitam a geografia mítica: presenças dispersas no espaço, na névoa da escuridão, que agitam as profundezas da sensibilidade do homem. "Tudo lhe diz alguma coisa” (Dardel, 2011, p. 53). 
Na cruz temos o sinal da paixão e morte de Cristo e de tudo o que está ligado a ele, impregnado em nós. Inspirada pelo lirismo de João da Cruz, Stein (2004) explica que a cruz é o leito nupcial onde os amantes se encontram, onde o Amado gera na amada uma vida nova. "O primeiro a adormecer (morrer na cruz) é o Amado para somente depois adormecer a amada" (Stein, 2004, p. 258). A cruz é o caminho mais curto para o homem encontrar o Criador. O cristão que não carrega sua cruz, não entra numa relação de amor com Ele e não gera dentro de si a nova vida que o conduz ao céu. Na visão de Edith Stein, a diferença entre o caráter simbólico da cruz e da noite é que a cruz é sinal daquele que está relacionado com a cruz de Cristo quer seja de modo explicativo ou histórico, ao passo que a noite é a expressão cósmica da mística cosmovisão de São João da Cruz. (Stein, 2004). A filósofa assume, desta maneira, um sentido místico de símbolo, enquanto revelação do sagrado.

\section{Aproximações finais}

Penso! Penso geograficamente. Penso em simbologia na geografia. Como reconhecer aquilo que não conheço? Sentindo? Intuindo? Pressentindo? Vivendo? Dardel (2011) me auxilia nos questionamentos. Ele me sussurra: "as realidades geográficas representam um símbolo da alma" (Dardel, 2011, p. 44), certo acolhimento, certo afeto da Terra com o homem. A revelação se dá pela experiência; é como se o ser sentisse necessidade de existir, de se entrelaçar com a Terra e se embriagar num voo pelos ares do sagrado.

O estudo filosófico da obra joanina na perspectiva de Edith Stein - Ciência da Cruz -, é entendido como clarificação. A "Ciência da Cruz" esclarece as estruturas que tornam possíveis o conhecimento dos fenômenos místicos ocorridos durante a experiência de João da Cruz. Seu relato místico revela o encontro com o Divino. Vale ressaltar o que os místicos dizem: sentem Deus na alma. O simbólico revela o sagrado que, manifestando-se como algo exterior, ao ser interiorizado, demonstra o sofrimento que caracteriza a transformação da alma no processo de purificação.

Esse mergulho em Deus, no próprio amor, será visto como uma experiência plena de significado para o sujeito místico que conseguirá relatar suas vivências com as dificuldades próprias desse tipo de experiência que atinge o inefável. Através do relato místico, o sujeito poderá tentar buscar a essência dessa vivência. A experiência mística intenciona comunicar a experiência da verdade vivenciada pelo sujeito. E na fenomenologia que a experiência mística intenciona comunicar a experiência da verdade vivenciada pelo sujeito ou, de outro modo, se constitui em um caminho para ler o sagrado e a própria mística.

Experiência mística, experiência geográfica. Terra que se abre. $\mathrm{O}$ encontro com a Terra permite ao indivíduo se colocar, com sua singularidade, com sua sensibilidade, na Terra, condutora de significado, de valor. A experiência geográfica contém emoção, sentimento. Neste sentido, ela se assemelha muito à empatia de Edith cujo outro deve se abrir para o eu de modo que possa haver o ato empático, para apreender a experiência do outro. Ouso dizer que é se deixar levar, estar em devaneio com a Terra que nos acolhe. É sair da noite obscura do mistério, se abrir para o que irá se revelar na luz, em nossa realidade geográfica. Perceber o simbólico em Edith Stein me ampara na maneira de compreender experiências geográficas que se revelam, de interpretar um sentido percebido, de ser no mundo. O simbólico de Edith Stein me inspira à geograficidade.

\section{Referências}

Dardel, E. (2011). O homem e a Terra: natureza da realidade geográfica. São Paulo: Perspectiva.

Heidegger, M. (2010). A origem da obra de arte. São Paulo: Edições 70.

Stein, E. (2004). Escritos espirituales: en el Carmelo teresiano 1933-1942. (Obras completas - Tomo V). Monte Carmelo; Vitoria: El Carmen.

Stein, E. (2004). Sobre el problema de la empatía. Madrid: Editorial Trotta S. A.

Teresa de Ávila, S. J. (2015). Castelo interior ou moradas. Petrópolis/RJ: Vozes.

Virgínia de Lima Palhares - Possui Graduação, Mestrado e Doutorado em Geografia pela Universidade Federal de Minas Gerais. Atualmente é Professora Adjunta do Departamento de Geografia do Instituto de Geociências da Universidade Federal de Minas Gerais. É lider do Núcleo de Pesquisa em Geografia Humanista - NPGEOH, no Instituto de Geociências da Universidade Federal de Minas Gerais é Professora do Instituto de Geociências da Universidade Federal de Minas Gerais. Endereço Institucional: Rua Fernandes Tourinho, 840 apto. 501 - Funcionários, CEP: 30112000 - Belo Horizonte - Minas Gerais. E-mail: palhares.vi@gmail.com

Recebido em 26.04.16 Primeira Decisão Editorial em 02.06.16 Aceito em 22.06.16 